\title{
Anterolateral Retroperitoneal Approach of Thoraco-lumbar Spine; A Study of 20 Cases
}

\author{
HARADHAN DEB NATH ${ }^{1}$, ZILLUR RAHMAN ${ }^{2}$, MAINUDDIN ${ }^{3}$, KAMAL UDDIN $^{4}$, LUTHFAR RAHMAN ${ }^{5}$, \\ MD AMINUL ISLAM ${ }^{6}$, ANM FAZLUL HAQUE ${ }^{7}$.
}

\begin{abstract}
:
This cross sectional study was done from April 2005 to November 2009 in the department of Neurosurgery of Chittagong Medical College Hospital. We have studied 20 patients of $D_{12}, L_{1}, L_{2} \& L_{3}$ fracture with lower limb weakness. Data were collected by a brief history, clinical examination, surgery \& postoperative follow up. Most of the sufferers were male (90.00\%). The age groups were $21-40$ years gripped the major proportion (50.00\%) of the patients. The commonest causes of injury were fall from height (60.00\%). The majority of patients had been suffering from $L_{1}$ fracture (45.00\%). The most (90.00\%) of the sufferers had parapareses. The highest groups of patients (90.00\%) improved after surgery. So, the study concludes that the anterolateral decompression, fusion \& fixation is one of the best options of treatment of throracolumbar spine fracture.
\end{abstract}

Key words: Anterolateral retroperitoneal, thoracolumber spine.

\section{Introduction:}

Anterolateral retroperitoneal approach is a easy approach specially for the surgeons those who are oriented with abdominal surgery. In this procedure anterior decompression can done by direct vision to the thecal sac. In case of lumbar or thoracic spine injury where posterior column of spine remains intact, no need to destroy posterior column. For this advantage we inspired to do the study to see the outcome after surgery.

The introduction of the anterior approach to the lumbar spine was initially designed for treatment of tuberculosis. In 1934, Ito and associates ${ }^{1}$ reported on the replacement of a diseased vertebral body by using either tibial or rib autograft. Hodgson and colleagues $^{2-4}$ obtained international recognition when they described the anterior surgical approaches to the spine and reported on Pott's disease using anterior spinal fusion surgery.
Subsequently Kelly and Whitesides ${ }^{5}$, Fountain ${ }^{6}$, and Hohlman and Eismont ${ }^{7}$ have applied the surgical principles to the management of trauma to the spine. Other authors have described anterior spinal surgery for various other conditions ${ }^{8-10}$.

The retroperitoneal approach was developed from the standard flank incision that had been used for lumbar sympathectomies. In the 1950s, Harmon popularized its application to spinal surgery, using this exposure to fuse the lumbar spine in the treatment of degenerative disk disease ${ }^{11}$. Compared with the transpertioneal route, the retroperitoneal approach provides the necessary exposure of the vertebral bodies and decreased risk of visceral and vascular injury. Unlike the lateral extracavitary approach, this exposure requires no manipulation of nerve roots and avoids the destabilizing effects of dissecting the posterior musculature. Its disadvantages include unilateral

1. Assistant Professor of Neurosurgery, BSMMU, Dhaka.

2. Professor Neurosurgery Shaheed Suhrwardy Medical College, Dhaka.

3. Associate Professor Neurosurgery, Rangpur Medical College, Rangpur.

4. Associate Professor of Neurosurgery Chittagong Medical College, Chittagong.

5. Professor of Neurosurgery, Rangpur Medical College, Rangpur.

6. Department of Neurosurgery, $\mathrm{CMH}$, Dhaka.

7. Associate Professor of Anaesthesia, Mymenshing Medical College. 
exposure and the anatomic obstacles encountered if a right-sided approach is required. Despite these limitations, the retroperitoneal approach provides excellent visualization, allowing surgeons to identify the neural elements and thecal sac to gain access from $L_{2}$ through $L_{5}$. Either a midline or a lateral exposure can be used to enter the retroperitoneal space; the primary distinction is the position of the skin incision and the degree of muscle transaction.

\section{Anterolateral Retroperitoneal Approach:}

A flank incision is used to start the ventrolateral retroperitoneal approach. The patient is placed in a lateral decubitus position with appropriate padding to avoid pressure ulcerations and neuropathies. The patient is positioned so that flexion of the operating table opens the space between the iliac crest and costal margin. The incision begins in the postaxillary line between the ribs and iliac crest and follows an inferior oblique course to the lateral edge of the rectus sheath. The level of the incision depends on the desired level of exposure. For lesions of the upper lumbar spine, the incision should be made above the umbilicus along the $11^{\text {th }}$ or $12^{\text {th }}$ rib. The rib can be resected to improve exposure and to provide a substrate for a fusion. For lesions in the midlumbar spine, the incision starts at the level of the umbilicus. The lower lumbar spine is accessed through an incision superior to the midpoint, between the umbilicus and sysmphysis pubis. Exposure of the lumbosacral junction is obtained through an incision inferior to this point.

In reality it is an anterolateral view of the vertebrae that allows access to the segmental vessels, vertebral body, pedicle, and transverse process, as well as the spinal canal and its contents. Clinically, this approach is most commonly used in the treatment of fractures, infection, or tumours to anteriorly decompress the neural elements. It is also frequently used in scoliosis procedures in which anterior release with or without anterior interbody fusion is performed over several levels of the lumbar spine.

The retroperitoneal approach provides an anterolateral view of the spine and at $\mathrm{L}_{4}$ and above the great vessels are not in the way. The iliac vessels do cross over the body of $L_{5}$ laterally in many patients, and access to the $L_{5}$ body and $L_{5}-S_{1}$ disk space can be limited with a retroperitoneal approach.
The skin incision is an oblique one that can be made over the $12^{\text {th }}$ rib or a few centimeters inferior to the $12^{\text {th }}$ rib. If access to $T_{12}$ or $L_{1}$ is needed. Making the incision over the $12^{\text {th }}$ rib and removing it provides the best exposure in the upper lumbar area. For $\mathrm{L}_{2}$ and lower, one can either remove the $12^{\text {th }}$ rib or make the incision halfway between the rib cage and the iliac crest. If one prefers the slightly higher incision, the $12^{\text {th }}$ rib is simply dissected out and removed; the remaining transversalis fascia is incised and this exposes the retroperitoneal space ${ }^{12}$.

\section{Materials \& Methods:}

The study was carried out in the department of Neurosurgery, Chittagong Medical College Hospital, Chittagong. The study was undertaken during April 2006 to November 2009.

Cases were selected following the inclusion \& exclusion criteria

1. Inclusion Criteria:

- Patients of either sex admitted with incomplete lumbar spine injury.

\section{Exclusion criteria:}

- Those patients who were operated second time due to complication excluded in this study.

- Complete injury.

Data was collected in a form regarding clinical presentation. Clinical examination, investigating procedure, postoperative evaluation \& only those patients who gave consent were in concluded in the study.

Results:

Table-I

Distribution of patients by age $(n=20)$

\begin{tabular}{lcc}
\hline Age in years & Number & Percentage \\
\hline $1-20$ & 06 & 30.00 \\
$21-40$ & 10 & 50.00 \\
$41-60$ & 03 & 15.00 \\
$\geq 61$ & 01 & 5.00 \\
\hline Total & 20 & 100.00 \\
\hline
\end{tabular}

A total of 20 patients of different age group was selected.

It was revealed that the highest age groups were $21-40$ years (50.00\%). Only 5.00\% were above 61 years age (Table I). 
Table-II

Distribution of patients by causes of compressive fracture $(n=20)$

\begin{tabular}{lcc}
\hline Causes & Number & Percentage \\
\hline Fall from height & 12 & 60.00 \\
Road traffic accident & 04 & 20.00 \\
Fall of heavy object on back & 02 & 10.00 \\
Fall by Slepage of foot & 01 & 05.00 \\
Pathological fracture & 01 & 05.00 \\
\hline Total & 20 & 100.00 \\
\hline
\end{tabular}

The table II showed that the causes of occurrence were fall from height $(60.00 \%)$, road traffic accident (207), fall of heavy object on back (10\%), fall by sleeping of foot $(05 \%)$, pathological fractures (05\%).

Table-III

Distribution of patients by site of compression $(n=20)$

\begin{tabular}{lcc}
\hline Site & Number & Percentage \\
\hline $\mathrm{L}_{1}$ & 09 & 45.00 \\
$\mathrm{D}_{12}$ & 05 & 25.00 \\
$\mathrm{~L}_{2}$ & 04 & 20.00 \\
$\mathrm{~L}_{3}$ & 02 & 10.00 \\
\hline Total & 20 & 100.00 \\
\hline
\end{tabular}

From table III it was evident that the commonest site of compression was at $L_{1}$ vertebrae $(45.00 \%)$, followed by $\mathrm{D}_{12}$ fracture (25.00\%).

Table-IV

Distribution of patients by type of weakness $(n=20)$

\begin{tabular}{lcc}
\hline Clinical features & Number & Percentage \\
\hline Paraparesis & 18 & 90.00 \\
Monoparesis & 02 & 10.00 \\
Bladder dysfunction & 10 & 50.00 \\
Bladder \& Bowel dysfunction & 03 & 15.00 \\
Sexual dysfunction & 02 & 10.00 \\
Bowel dysfunction & 02 & 10.00 \\
Bladder, Bowel \& Sexual & 02 & 10.00 \\
dysfunction & & \\
Intact autonomic function & 01 & 05.00 \\
intact & & \\
Sensory function impaired & 18 & 90.00 \\
\hline
\end{tabular}

Table IV showed that the most of the sufferers had paraparesis $(90.00 \%)$, the remaining $10.00 \%$ had monoparesis. The result revealed that the most of the patient $(40.00 \%)$ had suffered from bladder dysfunction. In was documented that $(90.00 \%)$ of the patients improved after surgery.

Table-V

Distribution of patients by type of modified MacNab's outcome score, autonomic function and sensory function outcome

\begin{tabular}{lcc}
\hline MacNab's outcome score & Number & Percentage \\
\hline Excellent (No pain) & 08 & 40.00 \\
Good (Occasional radicular pain) & 09 & 45.00 \\
Fair (Some improvement of functional capacity, still handicapped) & 01 & 5.00 \\
Poor (Continuous symptoms of root involvement) & 02 & 10.00 \\
Autonomic function & & \\
Improvement of bladder function ( $n=10)$ & 06 & 60.00 \\
Improvement of bladder \& bowel dysfunction ( $n=3)$ & 01 & 33.33 \\
Improvement of sex dysfunction ( $n=2)$ & 01 & 50.00 \\
Improvement of bowel dysfunction ( $n=2)$ & 01 & 50.00 \\
Improvement of bladder, bowel \& sexual dysfunction (n=2) & 01 & 50.00 \\
Sensory function & & \\
Improvement of sensory dysfunction ( $n=18)$ & 16 & 88.89 \\
\hline
\end{tabular}


The above table $V$ showed the number of patients and the percentage according to MacNab's outcome score, autonomic function and sensory functions.

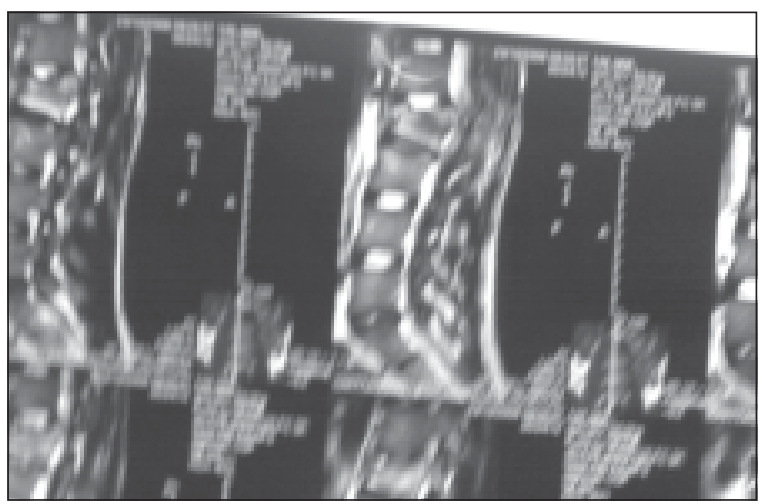

Fig.-1: MRI of L/S Spine Shows Compressive fracture at $L_{2}$

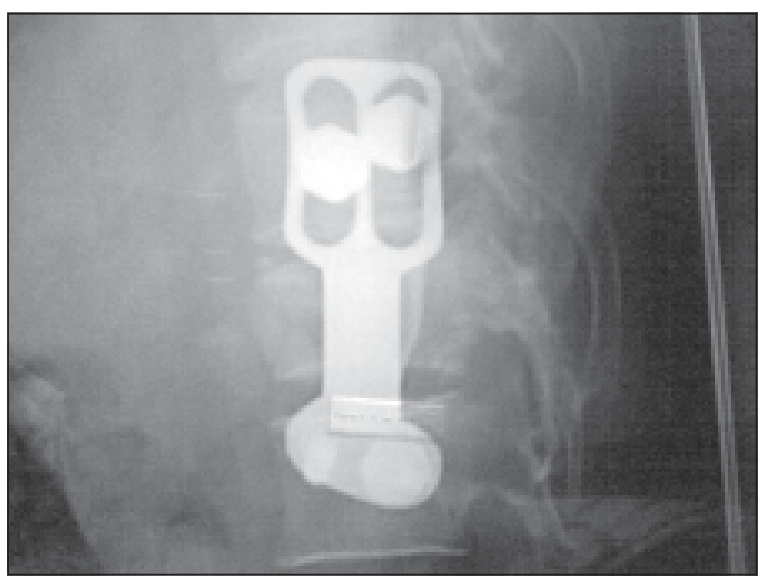

Fig.-2: Another figure of $Z$ plate fixation

\section{Discussion:}

This is a cross sectional study. In this study the most of (90.00\%) the sufferer were male. This study showed commonest age groups were $21-40$ years (50.00\%). In previous study commonest age groups were $21-40$ years $(75.00 \%)^{13}$.

It was documented that male were affected more than female (90.00\%). In previous study males (84.00\%) were affected predominantly. Previous Authors mentioned that the commonest causes of injury were road traffic $(60.00 \%)^{13}$ accidents. In this study commonest causes of injury were fall from height (60.00\%).
In previous literature it was found $\mathrm{L}_{1}$ fracture was the highest (53.33\%) site of fracture ${ }^{13}$.

In present study it was found that the $45.00 \%$ of sufferer had $L_{1}$ fracture. The second highest was $\mathrm{D}_{12}$ fracture (25.00\%). Present study showed $90.00 \%$ of patient had parapares, $10.00 \%$ had manoparesis and $50.00 \%$ patient had bladder dysfunction. Others had bowel and sex dysfunction. Fusion done with autologus bone graft from iliac crest. Fixation was done with titanium Z plate \& screw in cases of $85.00 \%$ of patients.

In case of $15.00 \%$ patients fixation was done with titanium cages \& bone chips. It was revealed that excellent improvement occurred in $8(40 \%)$ cases, good recovery occurred in $9(45 \%)$ cases, fair recovery occurred in $1(5 \%)$ cases and $2(10 \%)$ had poor outcome. Among the autonomic dysfunction, bladder function improved in 6(60\%) cases, bladder and bowel function improved in 1(33.33\%) case and sexual dysfunction improved in $1(50 \%)$ case. Among the 20 cases 18(90\%) patients had sensory dysfunction. After surgery in $16(88.89 \%)$ cases sensory dysfunction improves.

Keneda et al, reported $64.00 \%$ of their patients had excellent and $28.00 \%$ had good outcomes, $6.00 \%$ showing fair and $2.00 \%$ demonstrats poor outcome $^{14}$.

Three (15\%) had wound infection, which was treated by antibiotic therapy after wound swab culture \& dressing. The $05.00 \%$ of patients had one screw displacement. But the patient was stable.

One (05.00\%) of patient had excessive peroperative bleeding by injury of lumbar vessels \& treated by ligation of vessels and $05.00 \%$ of patient another had respiratory distress with pulmonary oedema and pneumonia which was managed by $\mathrm{O}_{2}$ therapy, proper antibiotic, morphine \& frusemide injection. There was no mortality.

\section{Conclusion:}

Patient with incomplete spinal cord injury showed good to excellent recovery and could be mobilized early with external support by anterolateral retroperitoneal approach with Z plate fixation. 


\section{References:}

1. Ito H, Tsuchya J, Asami G. A new radical operation for Pott's disease, J Bone Joint Surg 1934; 16:499.

2. Hodgson AR, Stock FE. Anterior spine fusionA preliminary communication on the radical treatment of Pott's disease and Pott's paraplegia. Br J Surg 1956; 44:266.

3. Hodgson AR, Stock FE. Anterior spine fusion for the treatment of tuberculosis of the spine. J Bone Joint Surg Am 1960; 42:295.

4. Hodgson AR, Stock FE, Tany HSY. Anterior spine fusion, Operative approach and pathologic findings in 412 patients with Pott's disease of the spine. Br J Surg 1960; 44:172.

5. Kelly RP, Whitesides TE Jr. Treatment of lumbodorsal fracture dislocations. Ann Surg 1968; 167:705.

6. Fountain SS. A single-stage combined surgical approach for vertebral resection. J Bone Joint Surg Am 1979; 61:1011.

7. Bohlman HK, Eismont FJ. Surgical techniques of anterior decompression and fusion for spinal care injuries. Clin Orthop 1981; 154:57.
8. Cotler HB, Cotler JM, Stoloff A. The use of autografts for vertebral body replacement of the thoracic and lumbar spine. Spine 1985; 10:748.

9. Flynn JC, Hogue MA. Anterior fusion of the lumbar spine. J Bone Joint Surg 1979; 61:1143.

10. Kozak JA, O'Brien JP. Simultaneous combined anterior and posterior fusions: An independent analysis of a treatment or the disabled low-back pain patient. Spine 1990; 15:322.

11. Harmon P. Anterior extraperitoneal lumbar disk excision and vertebral body fusion. Clin Orthop 1960; 18:169-84.

12. Aydin E, Solak AS, Tuzuner MM. Z-plate instrumentation in thoracolumbar spinal fractures. Bull Hosp Jt Dis 1999; 58:92-7.

13. Sahoo PK, Singh $P$, Bhatoe HS. Anterior Thoracolumbar fixation for Management of Thoracolumbar spine injury, 2004; 1, 49-54.

14. Kaneda K, Kuniyoshi A, Fujiya M. Burst fractures with neurologic deficits of the thoracolumbar spine- Results of anterior instrumenation. Spine 1984; 9:788-95. 